\title{
Robô Euroi: Estratégias Matemáticas para desenvolver o Pensamento Computacional
}

\author{
Douglas Silva de Melo",2, Fernanda Gabriela de Sousa Pires ${ }^{1,2}$, José Carlos da Silva \\ Duarte Filho $^{1,2}$, Robson James dos Reis Silva Junior ${ }^{1}$ \\ ${ }^{1}$ Licenciatura em Computação - Universidade do Estado do Amazonas (UEA) \\ Av. Darcy Vargas, 1.200- 69050-020 - Manaus - AM - Brazil \\ ${ }^{2}$ Laboratório de Tecnologias Educacionais - Universidade do Estado do Amazonas \\ Manaus, AM - Brazil \\ \{dsm.lic17, fpires,rjrsj.lic17, jcsdf.inf\} @uea.edu.br
}

Resumo: O presente artigo relata o processo de desenvolvimento do jogo educacional Robô Euroi, um game de ação e estratégia, desenvolvido na engine Construct e tem como proposta, auxiliar no desenvolvimento do pensamento computacional utilizando fundamentos matemáticos, de forma implícita. As missões são propostas através de enigmas algorítmicos em que o conhecimento sobre operações fundamentais matemáticas e estruturas condicionais são essenciais para a resolução dos problemas. Sua construção teve como base teórica os fundamentos de Pensamento Computacional e processos cognitivos de aprendizagem fundamentados em neurociência. O aplicativo é destinado para crianças na faixa etária de 8anos, mas por seu caráter lúdico, é livre e recomentado para todos os públicos.

\section{Cenário de uso}

As tecnologias digitais estão presentes no dia a dia da sociedade, os jogos que em sua maioria ferramentas de entretenimento, podem ser utilizados como ferramentas educacionais, se criados de maneira a proporcionar situações que levem ao exercício da análise e da reflexão (Dichev \& Dicheva, 2017), embora muitas discussões venham sendo realizadas sobre esse tema.

Atualmente, um tema tem suscitado muitas discussões no cenário científico, o "Pensamento Computacional" defendido por Wing $(2017 ; 2006)$ como um conjunto de habilidades e competências que tem como fim a resolução de problemas cujo aporte está ancorado em métodos utilizados pela Ciência da Computação como a depuração, recursividade, generalização e decomposição na proposição de soluções tanto técnicocientíficos quanto na vida real, durante o dia a dia.

Resnick (2017) afirma que a aprendizagem ocorre por meio de métodos e situações inovadoras, que devam proporcionar aos aprendizes as oportunidades de pensar criticamente, defendendo assim que a fase de aprendizagem que ocorre durante o jardim de infância, deve seguir ao longo de toda a vida, promovendo experiências criativas e motivadoras. Os Parâmetros Curriculares Nacionais (PCN) apontam caminhos para a inserção do Pensamento Computacional nas escolas PCN (2002) em trechos como "reconhecer a informática como ferramenta para novas estratégias de aprendizagem pode contribuir de forma significativa para o processo de construção do conhecimento, nas diversas áreas". 
Mestre et al. (2015) discute a relação entre o Pensamento Computacional e Matemática em investigações empíricas utilizando questões de matemática disponibilizados do teste de PISA e conclui que entre nove conceitos de Pensamento computacional, seis deles estão presentes nas questões analisadas do teste. Considerando esse contexto, este artigo apresenta a produção de um jogo educacional com o objetivo de estimular o pensamento computacional por meio de fundamentos da matemática e é intitulado "Robô Euroi".

O jogo "Robô Euroi" é um jogo de plataforma 2D retrô, em que o personagem Robô Euroi, tem a missão de resgatar astronautas perdidos no espaço e para isso precisa arriscar-se em planetas desconhecidos. É um jogo do estilo plataforma-estratégia que estimula o jogador a resolver questões lógicas relacionadas as operações básicas da matemática para não ficar sem combustível.

\section{Desenvolvimento}

Para desenvolvimento do jogo, foi utilizado o construct $2^{l}$, uma engine que possibilita e a criação de jogos 2D, o software tem a sua versão paga e livre, no presente jogo desenvolvido foi utilizado a versão livre que possui algumas limitações.

A engine utilizada é baseada no HTML5 e a programação é feita de forma visual, por isso não exige muitos conhecimento de programação, o jogo é destinado a plataformas mobiles, tablets e celulares com sistema operacional android versão mínima de 4.9.

O desenvolvimento do aplicativo deu-se de acordo com o processo descrito a seguir e representado no diagrama 1 abaixo.

Diagrama 1. Diagrama de ciclo de software

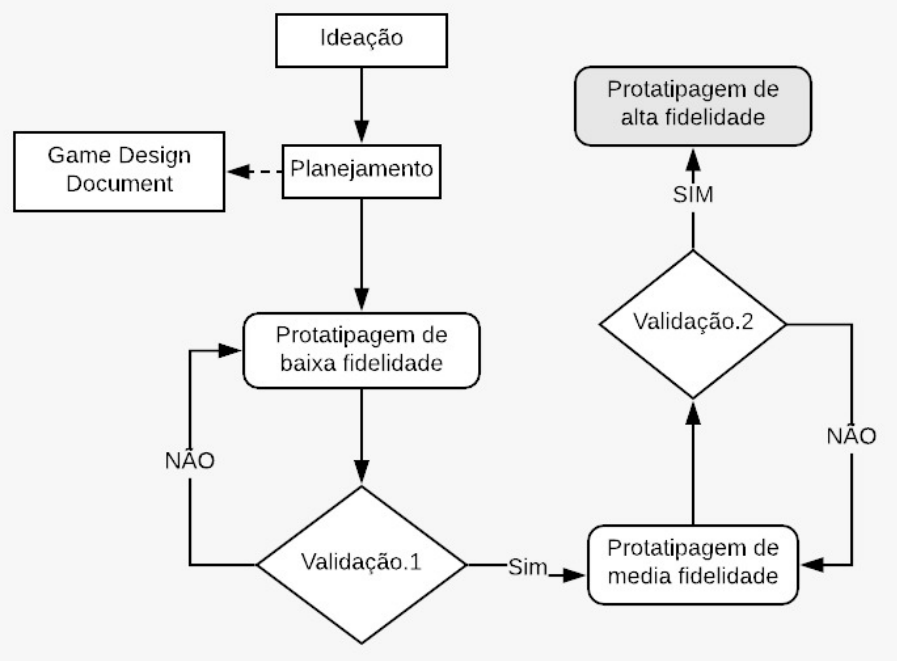

Ideação: a ideação é para Brown Brown (2009) é o processo no qual as ideias e conceitos são elaboradas com o intuito de criar inovações sobre os problemas observados,

\footnotetext{
${ }^{1}$ Construct 2 - https://www.scirra.com/construct2
} 
utilizou-se de Brainstorns para a troca de ideias com os integrantes da equipe. Então foi definido a temática e o enredo do jogo, e para obter um referencial de desenvolvimento e criar um jogo disruptivo que alinhe os critérios educacionais com jogos de entretenimento foi realizado um levantamento de softwares. Os jogos encontrados que compartilham características comuns foram:

Math Blaster de 1983, é um jogo para desktop que trabalha com fundamentos matemáticos, se passa num cenário espacial, com diversos desafios e devem responder corretamente uma pergunta matemática para assim poder atacar os inimigos.

Dan The Man, é um jogo de ação e plataforma, o personagem tem que derrotar diversos inimigos, com o objetivo de salvar a princesa, possui um estilo $2 \mathrm{D}$ de plataforma e é caracterizado por seu aspecto ergonômico em relação aos elementos de HUD.

Super Dangerous Dungeons, é um jogo de plataforma, não educacional, o personagem é um caçador de tesouros, que passa por diversos cenários para completar seus objetivos, o designer estilo pixalizado de 8 bits desse jogo foi o ponto que chamou atenção.

Planejamento: no planejamento foram definidas as etapas a serem seguidas para o desenvolvimento do jogo, dado início ao cronograma de atividades e documentação do processo, para isso foi usado o Game Design Document, Rogers (2014).

Prototipagem Baixa Fidelidade: Também chamados de Rascunhos e Sketches a princípios, nos primeiros moldes do jogo foram feitos por intermédio de desenhos, de forma simples e intuitiva, com o objetivo demonstrar ideia inicial do jogo de forma visual, apresentando a mecânica, Storyboard e o Gameplay.

Validação 1: a primeira validação consistiu na análise dos primeiros protótipos com o objetivo de verificar se os requisitos definidos no planejamento estão sendo atendidos. Assim como para apresentar novas funcionalidades e corrigir possíveis equívocos.

Protótipo de média fidelidade: após os resultados obtidos na primeira validação e implementação das alterações, o protótipo de média fidelidade foi desenvolvido para apresentar as funcionalidades reais do aplicativo. Para esta etapa foi utilizada o constructo 2 .

Validação 2: a segunda validação teve como objetivo analisar, além das características descritas na documentação, a experiência do usuário. Para isso foram utilizados os testes de usabilidade de Nielsen (1993) e o testes de percurso cognitivo de Wharton (1994).

Prototipagem de Alta fidelidade: o protótipo de alta fidelidade é a representação mais parecida possível com o produto que se deseja desenvolver. Estão presentes todas os requisitos e funcionalidades planejadas e descritas na documentação. Todas as correções e alterações sugeridas foram implementadas e o protótipo é deixado pronto para a versão final. Para criar um aplicativo que agrade ao usuário esta etapa contou também com a aplicação do teste de gameflow.

\section{Apresentação do Software}


O jogo Robô Euroi foi desenvolvido com o objetivo de fomentar o pensamento computacional através de fundamentos da matemática. Neste contexto, o jogo tem o objetivo de exercitar a associação de algarismos com quantidade, além de aplicar as operações aritméticas soma e subtração. Paralelo a isso, o jogador aplica o pensamento computacional para resolver os problemas do jogo, por meio da decomposição, abstração e algoritmos.

No link é possível assistir ao vídeo demonstrativo do jogo: https://www.youtube.com/watch?v=aVrH8u4Fj6I

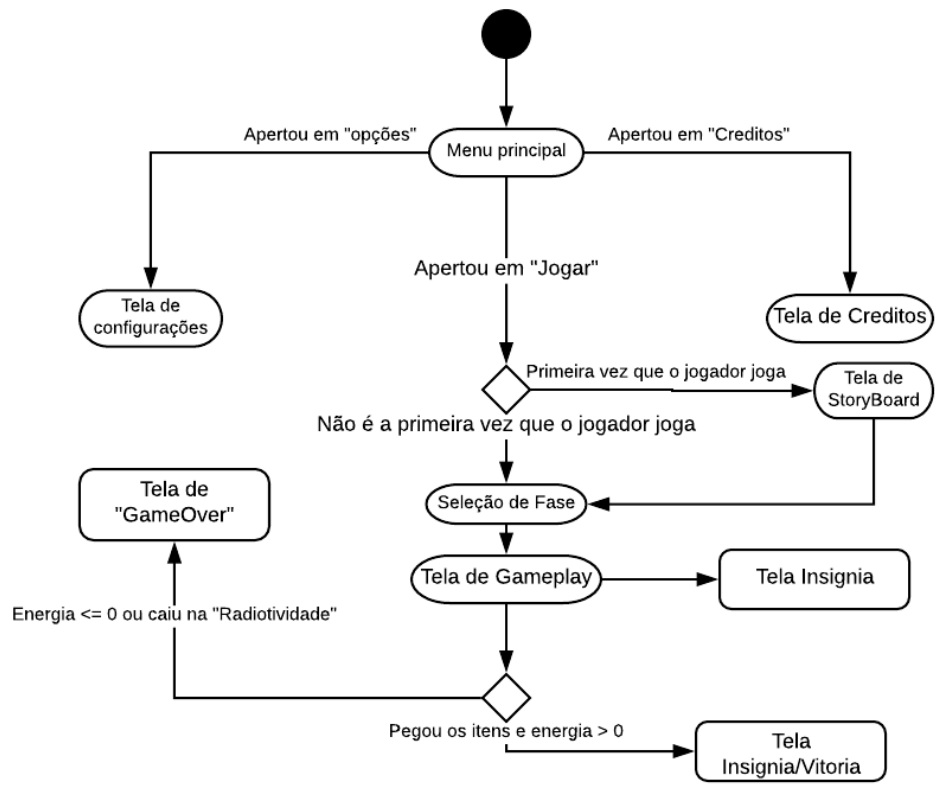

Diagrama 2. Diagrama de Fluxo de Tela

\subsection{Conceito de jogo}

Robô Euroi é um jogo de plataforma 2D retrô, Euroi (personagem principal), terá que aventurar-se em planetas desconhecidos (Figura 1) para salvar os astronautas, e para isso ele precisará enfrentar diversos obstáculos. Os mundos desconhecidos possuem níveis de energias diferentes, algumas podem causar danos a Euroi e outras fornecem energia. Para salvar os astronautas o Robô precisa recolher as peças da nave espacial que estão espalhadas por esses planetas. Por tanto é necessário tomar muito cuidado para não deixar que sua energia chegue a zero. Por isso o jogador tem a missão de controlar Euroi nas tomadas de decisões que precisam ser feitas para alcançar as peças perdidas e retornar para a Terra com os astronautas. 

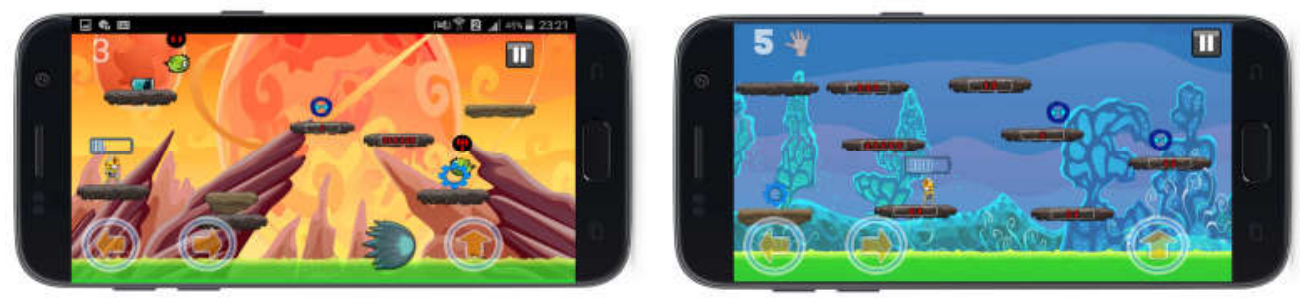

Figura 1. Mundo do jogo

\subsection{Mecânica do jogo}

O jogo possui uma mecânica simples, são utilizados comandos pelo touchscreen para mover o personagem nas três direções possíveis, direita, esquerda e cima (pulo).

O objetivo é recolher as peça e ferramentas espalhados pelas fases. Mas para isso é preciso passar pelas plataformas flutuantes, porém algumas dessas plataformas causam certos danos em Euroi, roubando parte de seu combustível.

As plataformas indicam o quanto de combustível é retirado caso toque nela por isso o jogador deve planejar exatamente em quais plataformas pular para que a energia não chegue a zero. Além disso, também é usado energia para atacar inimigos. Por exemplo, Euroi está com 4 barras de energia e a sua frente tem uma plataforma que subtrai 3 energias do robô, ao cair nela, o personagem fica com 1 carga apenas, adiante existe um inimigo e é preciso gastar 1 energia para atacar, logo, a sua energia chegará a zero. Também é possível encontrar pelo caminho energias positivas que dão um certo quantidade de combustível ao robô.

É necessário recolher todos os itens que estão na fase (Figura 2) para que possa seguir para o próximo mundo.
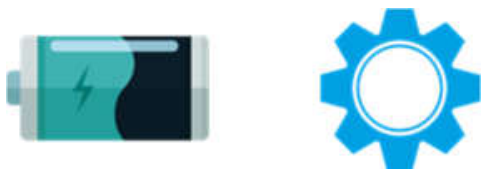

Figura 2. Itens coletáveis

\subsection{Descrição das telas do Robô Euroi}

$\mathrm{Na}$ Figura 3 é apresentado o menu principal do jogo com botões de iniciar, configurações e créditos. A figura 4 representa tela de opções, possui os botões de acesso rápido, que mudam o som do jogo e ativam o "auxílio associativo". A figura 5 representa a tela de crédito que possui informações relacionadas aos desenvolvedores do jogo.

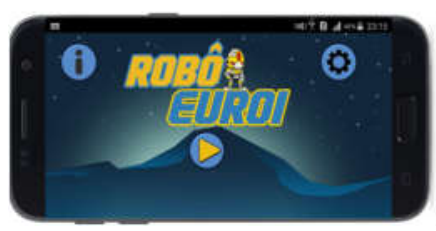

Figura 3. Tela de menu principal

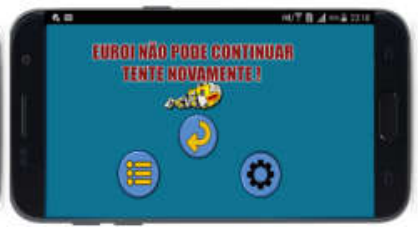

Figura 4. Tela de Opções

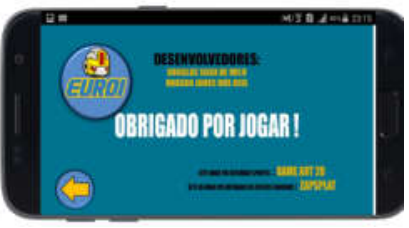

Figura 5. Tela de créditos 
Ao apertar no botão de iniciar jogo, o usuário segue para a tela de storytelling (figura 6), é demonstrando a história do jogo através de diálogos entre personagens, caso seja a primeira vez jogando o jogo, caso não, o jogador é levado a tela de seleção de fases diretamente.

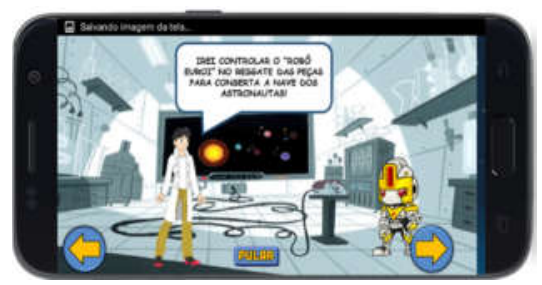

Figura 6. Tela de Storytelling

Na figura 7 o jogador tem a opção de escolher as fases que estão disponíveis, as fases bloqueadas estão com um cadeado na frente, além escolha de fase, também existe o botão de insígnias, que leva a tela de recompensas (Figura 8) dado ao jogador no jogo.

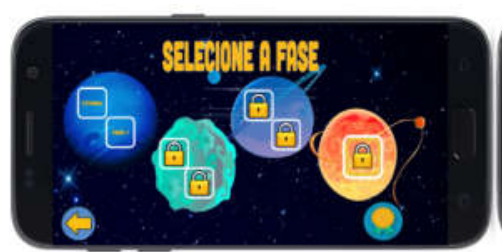

Figura 7. Tela de Seleção de Fases

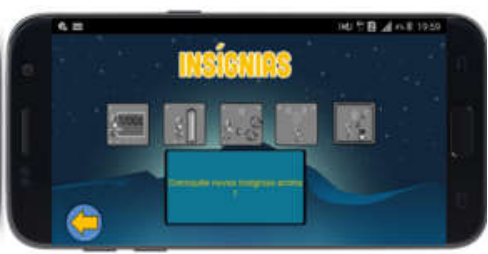

Figura 8. Tela de Insígnias

$\mathrm{Na}$ figura 9 apresenta a tela de gameplay de uma das fases e o jogador deve controlar Euroi em sua missão de resgate. Quando a fase é concluída é apresentada um feedback de vitória (Figura 10), caso contrário o feedback de GameOver (Figura 11).

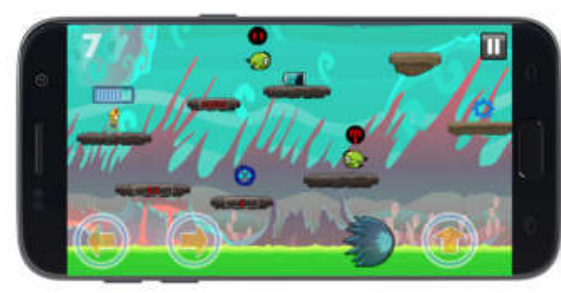

Figura 9. Tela de Gameplay

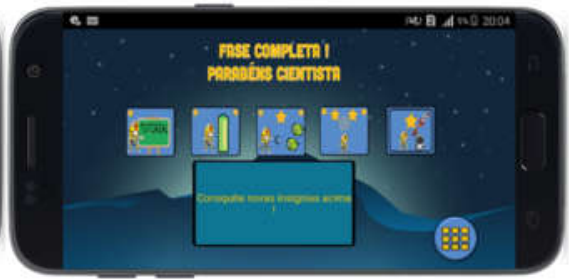

Figura 10. Tela de vitória

\section{Considerações finais}

Os resultados alcançados com o teste de Gameflow que analisa os critérios de concentração, desafios, habilidades do Jogador controle, Interação, Imersão, Feedback e Objetivos a classificação atribuída pelos usuários predominas as notas 3 e 4 em uma escola de 0 a 5. Em relação as 10 heurísticas de usabilidade de Nielsen o aplicativo aqui descrito atende a 6 deles. O percurso cognitivo indicou que o jogo proporciona os objetivos de aprendizagem pretendidos, proporcionando aos jogadores a desenvolver o pensamento computacional por meio de princípios matemáticos 
VII Congresso Brasileiro de Informática na Educação (CBIE 2018)

Anais dos Workshops do VII Congresso Brasileiro de Informática na Educação (WCBIE 2018)

\section{Referências}

Brown, T. (2009). Change by design.

Dichev, C., \& Dicheva, D. (2017). Gamifying education: what is known, what is believed and what remains uncertain: a critical review. International Journal of Educational Technology in Higher Education, 14(1), 9.

MEC. (2002). Parâmetros Curriculares Nacionais (Ensino Médio). Secretaria da Educação Média e Tecnológica/Brasília: MEC/SEMT.

Mestre, P., Andrade, W., Guerrero, D., Sampaio, L., da Silva Rodrigues, R., \& Costa, E. (2015). Pensamento Computacional: Um estudo empírico sobre as questões de matemática do PISA. Paper presented at the Anais dos Workshops do Congresso Brasileiro de Informática na Educação.

Nielsen, J. (1993). Response times: the three important limits. Usability Engineering.

Resnick, M. (2017). Lifelong Kindergarten: Cultivating Creativity Through Projects, Passion, Peers, and Play: MIT Press.

Rogers, S. (2014). Level Up! The guide to great video game design: John Wiley \& Sons.

Wharton, C. (1994). The cognitive walkthrough method: A practitioner's guide. Usability inspection methods.

Wing, J. (2017). Computational thinkinglu2019s influence on research and education for all. Italian Journal of Educational Technology, 25(2), 7-14.

Wing, J. M. (2006). Computational thinking. Communications of the ACM, 49(3), 33-35. 